\title{
Sleep hygiene awareness: its relation to sleep quality and diurnal preference
}

\author{
Bogdan loan Voinescu* and Aurora Szentagotai-Tatar
}

\begin{abstract}
Background: Sleep hygiene is a core component for psychological treatments of insomnia and essential for maintaining a satisfactory sleep. Our study aimed to measure the sleep hygiene awareness and the self-reported quality of sleep among three age groups (young adults, adults and middle-aged adults) and to determine their relation. We also measured their relation with diurnal preference.

Methods: Using an online questionnaire, we surveyed six hundred fifty two participants, recruited nationwide from the community and from the students in three main cities in Romania.

Results: Sleep hygiene awareness was moderate on the whole and significantly worse in young adults (compared to the other age groups) and in those complaining of poor sleep (compared to those with good sleep). Sleep quality was average and linked positively with diurnal preference (the more evening oriented, the poorer the sleep). Diurnal preference was not found to play a role regarding sleep hygiene awareness.
\end{abstract}

Conclusions: Our results suggest that better sleep hygiene awareness does not necessarily guarantee better sleep quality and that it may actually be an indicator of dissatisfaction with the obtained sleep.

Keywords: Sleep hygiene, Sleep quality, Diurnal preference, Internet survey

\section{Background}

Sleep hygiene is a collection of behaviors and environmental conditions [1] that aim to ensure a restorative and good quality sleep and to avoid or to treat certain sleep disorders [2]. It is a core component of cognitivebehavioral therapy or multimodal therapies for insomnia [2-6], though its efficacy is questionable [7-11]. While doubtful in older adults [11], sleep hygiene has been reported to be effective in adolescents and young adults, probably because their sleep knowledge and practice are poor [12-15].

Students are notorious for insufficient and poor quality sleep and for irregular sleep habits, such as sleeping less during the week and longer during the weekends [15-20]. It has been found that students slept almost an hour less in 2001 compared to 1969 and that 68.3\% of them reported sleep problems, compared to 26.7 four decades before [16]. Even more, students seem to be

\footnotetext{
* Correspondence: bogdan.voinescu@ubbcluj.ro

Department of Clinical Psychology and Psychotherapy, Laboratory for the Research of Sleep Disorders and Circadian Psychobiology, The International Institute for the Advanced Studies of Psychotherapy and Applied Mental Health, Babeș-Bolyai University, Cluj-Napoca, Romania
}

unaware of the negative effects of sleep deprivation, such as consequences on psychological well-being $[20,21]$ and on academic performance $[22,23]$. On the other hand, sleep quality has been demonstrated to degrade as we age, both as a direct consequence of age and as an indirect result of various conditions (reviewed by Edwards et al. [24]). Unlike in the case of students, there is no consistent evidence that sleep durations are declining among adults worldwide [25].

Besides age, diurnal preference, sometimes known as morningness-eveningness, is also linked with the quality of sleep and with sleep hygiene awareness, as the evening types reported poorer sleep quality [19,26,27] and sleep knowledge [28]. Age has a significant effect on morningness-eveningness, too, in the sense that morningness increases with age $[29,30]$. Older people tend to go to and out of bed earlier than younger adults and have more trouble than younger adults adjusting to nightshift work and jetlag, at least in terms of sleep quality, subjective complaint, and performance measures [31].

Motivated by the inconsistencies in the sleep hygiene literature regarding the link between sleep hygiene 
awareness and sleep quality, we designed a study that also paid attention to concerns regarding the generalizability of research findings based on younger populations to older populations. We aimed to measure the sleep hygiene awareness and the self-reported quality of sleep among three age groups (young adults, adults and middle-aged adults) and the relation between them. We also aimed to examine their relation with the diurnal preference. Our hypotheses were that both poor sleep hygiene awareness and evening preference are linked with poorer sleep and that the evening chronotypes have worse sleep hygiene awareness compared to the morning ones.

\section{Methods}

\section{Participants}

Six hundred fifty two participants were recruited in a larger survey and were divided into three age groups: young (aged between $18-25$ years; $\mathrm{N}=360 ; 55.2 \%$ ), adult (aged between $26-45$ years; $\mathrm{N}=220 ; 33.7 \%$ ) and middleaged (between $46-65$ years; $\mathrm{N}=72 ; 11.1 \%$ ). The majority were women $(73.6 \%, \mathrm{~N}=480)$ (more details in Table 1 ). Most of the participants declared that they were students (38.7\%, $\mathrm{N}=252$ ), were not married $(69.0 \%$, $\mathrm{N}=450)$ and that their income is less than $£ 100(26.8 \%$, $\mathrm{N}=103$ ). All of the participants had attended high school, while $17.0 \%(\mathrm{~N}=111)$ had postgraduate studies.

\section{Instruments}

The Sleep Beliefs Scale(SBS) has twenty items and explores the awareness regarding the influence of substance use, behaviors, activities and thoughts on sleep, recording positive, negative or neither effect on sleep [28]. It specifically asks the respondents not to think of how their sleep is influenced in particular, but of how they believe these behaviors affect people in general. Most of the items record the negative answers as being correct. Though the authors recommend scoring correct answers with one point and incorrect ones (including all answers of "neither effect") with nothing, we used the scoring suggested by Digdon [14] in an extended scale. Thus, we scored correct answers as +1 , neutral ones (neither effect) as 0 and incorrect ones as -1 . The possible scores range between -20 and +20 , the higher the score, the better the awareness. The scale has been validated in Romanian with the original scoring [32].

The Sleep Condition Indicator (SCI) is a new insomnia self-report instrument [33] that consists of eight items that gather information on sleep patterns in the last month (minutes needed for falling asleep, minutes being awake during the night, number of problem nights in a week), sleep quality, impact of poor sleep, level of concern about poor sleep and history of poor sleep. It generates scores in the range 0 to 32 , the higher the value, the poor a person's sleep. ${ }^{\mathrm{a}}$ The scale has been found to have adequate psychometric properties in its Romanian translation [34].

The Composite Scale of Morningness (CSM) was chosen for determining circadian typology (morningness/ eveningness) as it is widely used worldwide and is available in several languages, including Romanian [35]. It contains 13 questions, most of them having four choices, with a Likert-type response format, and total scores range from 13 (extreme eveningness) to 55 (extreme morningness) [36]. As suggested by the authors and by Paine et al. [30], we calculated the cut-offs based on the 10/90 percentiles and age groups.

Table 1 Summary of descriptive data by age group and gender

\begin{tabular}{|c|c|c|c|c|}
\hline & Young & Adult & Middle-aged & Total \\
\hline Age & $21.9(\mathrm{SD}=1.8)$ & $32.9(\mathrm{SD}=5.7)$ & $54.24(S D=5.6)$ & $29.2(S D=10.9)$ \\
\hline \multicolumn{5}{|l|}{ Gender } \\
\hline Women & $80.0 \%(N=288)$ & $66.8 \%(N=147)$ & $62.5 \%(N=45)$ & $73.6 \%(N=480)$ \\
\hline Men & $20.0 \%(N=72)$ & $33.2 \%(N=73)$ & $37.5 \%(\mathrm{~N}=27)$ & $26.4 \%(N=172)$ \\
\hline Sleep beliefs scale & $8.6^{*}(4.5)$ & $9.7(4.5)$ & $10.1(3.6)$ & $9.2(4.5)$ \\
\hline Women & $9.3(4.4)$ & $10.4(4.4)$ & $10.5(3.0)$ & $9.7(4.3)$ \\
\hline Men & $6.3(4.3)$ & $8.4(4.5)$ & $9.4(4.4)$ & $7.7^{*}(4.5)$ \\
\hline Sleep condition indicator & $11.6(7.1)$ & $12.8(7.8)$ & $11.6(8.4)$ & $12.0(7.5)$ \\
\hline Women & $12.3(7.1)$ & $13.1(8.3)$ & $12.4(8.7)$ & $12.5(7.6)$ \\
\hline Men & $8.8(6.1)$ & $12.3(6.9)$ & $10.1(7.8)$ & $10.4(6.9)$ \\
\hline Composite scale of morningness & $32.7^{*}(6.6)$ & $36.3(7.4)$ & $40.9(6.3)$ & $34.8(7.4)$ \\
\hline Women & $32.5(6.8)$ & $36.5(7.1)$ & $41.0(7.2)$ & $34.5(7.4)$ \\
\hline Men & $33.5(5.9)$ & 36.1 (8.1) & $40.9(4.5)$ & $35.7(7.2)$ \\
\hline
\end{tabular}

Significant differences are starred. 


\section{Procedure}

Students attending the undergraduate and master degree programs of the Faculty of Psychology in Cluj-Napoca, Iași and Bucharest, Romania, were invited to participate in an online survey. They were given a web link with the description of the study and kindly ask to invite other participants from their acquaintances. In the same time, we recruited adults from the general community by online adverts posted on health related sites, as well as by adverts in local mass media in Cluj-Napoca, Romania. Participation was unpaid and all respondents received a brief interpretation of their scores on the completion of the questionnaires. The study was part of larger survey, was approved by the Ethics Committee of the Babeș-Bolyai University and is conform to international ethical standards.

\section{Data analysis}

Means and standard deviations were calculated for total or sub-total scores. As data were normally distributed, $\mathrm{T}$ test or ANOVAs were used to compare the differences between means, along with post hoc tests, using the Bonferroni procedures. Pearson Chi-Square test was used for estimating the significance of the differences between frequencies among various groups. Partial correlation (with controlling for age and gender) was used for calculating correlations between different variables. The level of significance was set at .05. Data analysis was performed with IBM SPSS Statistics 20.0.0 (IBM Corp., Armonk, NY, USA).

\section{Results}

\section{Sleep hygiene awareness}

As shown in Table 1, the awareness about sleep hygiene in our sample was moderate (mean score 9.2, range -3 to 20). Young adults scored lower than all the other age groups and ANOVA revealed that the differences were significant $\left[F(2,649)=5.9, p=0.003, \eta^{2}=0.018\right]$. Post- hoc comparisons using the Bonferroni procedure indicated that the mean scores were significantly different between young and adults $(p=0.012)$ and between young and middle-aged $(p=0.033)$, but not between adults and middle-aged participants. Looking at the whole sample, women reported significantly better sleep hygiene awareness than their male counterparts $[t(650)=5.2, p<0.001$, $\mathrm{d}=0.40]$. The three chronotypes reported almost similar levels of sleep hygiene awareness (details in Table 2).

\section{Sleep quality}

Sleep quality was average in all three age groups with no significant differences between them. The evening types complained of poorer sleep compared to the other types and ANOVA revealed that the differences were significant: the more evening orientated, the worse the sleep
Table 2 Average scores (standard deviations) in the used scales after grouping the participants by sleep hygiene awareness, sleep quality and diurnal preference (please see text for details)

\begin{tabular}{llll}
\hline Group & $\begin{array}{l}\text { Sleep } \\
\text { beliefs } \\
\text { scale }\end{array}$ & $\begin{array}{l}\text { Sleep } \\
\text { condition } \\
\text { indicator }\end{array}$ & $\begin{array}{l}\text { Composite } \\
\text { scale of } \\
\text { morningness }\end{array}$ \\
\hline Sleep hygiene awareness & & & \\
Low $(\mathrm{N}=139)$ & $2.9(2.2)$ & $10.3^{*}(7.2)$ & $34.9(6.9)$ \\
Intermediate $(\mathrm{N}=349)$ & $9.1(1.9)$ & $12.1(7.3)$ & $34.6(7.4)$ \\
High ( $=158)$ & $14.8(1.7)$ & $13.2(8.0)$ & $35.1(7.8)$ \\
Sleep quality & & & \\
Poor $(\mathrm{N}=140)$ & $10.9(4.5)$ & $23.1(3.3)$ & $33.2(8.6)$ \\
Intermediate $(\mathrm{N}=356)$ & $9.3(4.3)$ & $11.5(3.6)$ & $34.5(6.9)$ \\
Good ( $\mathrm{N}=150)$ & $8.1^{*}(4.6)$ & $2.9(1.7)$ & $37.2^{*}(6.6)$ \\
Diurnal preference & & & \\
Evening ( $=65)$ & $9.6(4.6)$ & $16.0^{*}(7.5)$ & $21.1(2.7)$ \\
Intermediate $(\mathrm{N}=499)$ & $9.1(4.4)$ & $11.7(7.7)$ & $34.8(4.9)$ \\
Morning $(\mathrm{N}=82)$ & $9.4(4.5)$ & $10.5(7.7)$ & $45.9(1.9)$ \\
\hline
\end{tabular}

Significant differences are starred.

$\left[F(2,649)=11.7, p<0.001, \eta^{2}=0.035\right]$; post hoc Bonferroni comparisons showed that the differences were significant amongst evening-morning types $(\mathrm{p}<0.001)$ and eveningintermediate ones $(\mathrm{p}<0.001)$. We found weak, negative and significant correlations between sleep quality and sleep hygiene awareness $(\rho=-0.116, p=0.03)$, as well as between sleep quality and morningness $(\rho=-0.285, p<0.001)$.

\section{Diurnal preference}

Total morningness scores were clearly raising with age: the older the group, the more morning oriented, and the effect size was moderate $[F(2,643)=49.5, p<0.001$, $\left.\eta_{\mathrm{p}}{ }^{2}=0.133\right]$; post hoc Bonferroni comparisons showed that the differences were significant amongst all three age groups $(p<0.001)$. We found no significant effect of gender on CSM scores.

\section{Sleep hygiene awareness and sleep quality}

To better understand the role sleep hygiene plays in the subjective sleep quality, we divided the sample by standard deviations $( \pm 1 S D)$, first according to their levels of sleep hygiene awareness (determined cut-off points were 5 and 13) and then according to their quality of sleep (calculated cut-off points were 5 and 19). We first compared the mean scores of sleep quality in the resulted three groups of sleep hygiene awareness (see Table 2). We hypothesized that those with high awareness will report better sleep. Those with worse sleep hygiene awareness reported significantly better sleep, while those with better awareness, poorer sleep $\left[F(2,649)=5.7, p=0.003, \eta^{2}=0.017\right]$; post hoc Bonferroni comparisons showed that the differences 
were significant amongst poor-good awareness $(p=0.003)$ and poor-intermediate awareness $(p=0.038)$.

We then compared the means of their sleep hygiene awareness in the resulted three groups of sleep quality (see Table 2). We hypothesized that those with better sleep will have report better sleep hygiene awareness. We found again significant differences between the three groups $\left[F(2,651)=7.1, p=0.001, \eta^{2}=0.021\right]$; post hoc Bonferroni comparisons showed that the differences were significant amongst poor-good sleep quality $(p=0.001)$ and between good-intermediate sleep quality groups $(p=0.020)$.

\section{Discussion}

Our study revealed that sleep hygiene awareness was moderate on the whole, but worse in the young adults. Sleep quality was average and linked positively with diurnal preference (the more evening oriented, the worse the sleep). The main findings are depicted in Figure 1.

Our results indicated levels of sleep awareness in line with findings from other countries, such as Croatia [37], England [38], Italy [28], Spain [28,39], Sweden [40], United States of America [8,12], Canada [14], Australia [41], Turkey [42], Hong Kong [15], India [43], Taiwan [44] or Ethiopia [45]. Unlike reports from the Western literature $[14,28]$ and like a previous study of ours [32], current data do not support the idea that evening types have poorer sleep hygiene awareness. Diurnal preference was linked with the quality of sleep, the evening type reporting poorer sleep, a fairly common finding worldwide $[19,26,27,46-49]$. Possible explanations are irregular sleepwake schedules, unhealthy sleep habits or a greater need for sleep in the evening types.

Age appeared to be an important factor affecting sleep hygiene awareness, but not sleep quality. Despite theoretically better sleep quality owing to natural plasticity and automaticity of sleep and lesser likelihood of disease that interferes sleep [24], young people report poor sleep quality $[12,18,45,50-53]$, possibly because they do not implement known techniques, due to the pressure of increased work, study or social demands. For the older participants, despite having better sleep hygiene awareness that should facilitate better sleep practices, these benefits may be of lesser extent taking into account the associated physiological or pathological changes that lead to a deterioration of sleep quality [24]. There is no consistent evidence that sleep duration is declining among adults worldwide (analyzed data showed that sleep duration decreased in six countries, increased in seven countries, and mixed results were detected in other two) [25]. Ohayon and colleagues calculated that adults' total sleep duration decreases with about 10 minutes per decade of age, while their sleep efficiency drops 3\% per decade, starting from 40 years of age [54]; they also showed that the majority of the changes seen in adult

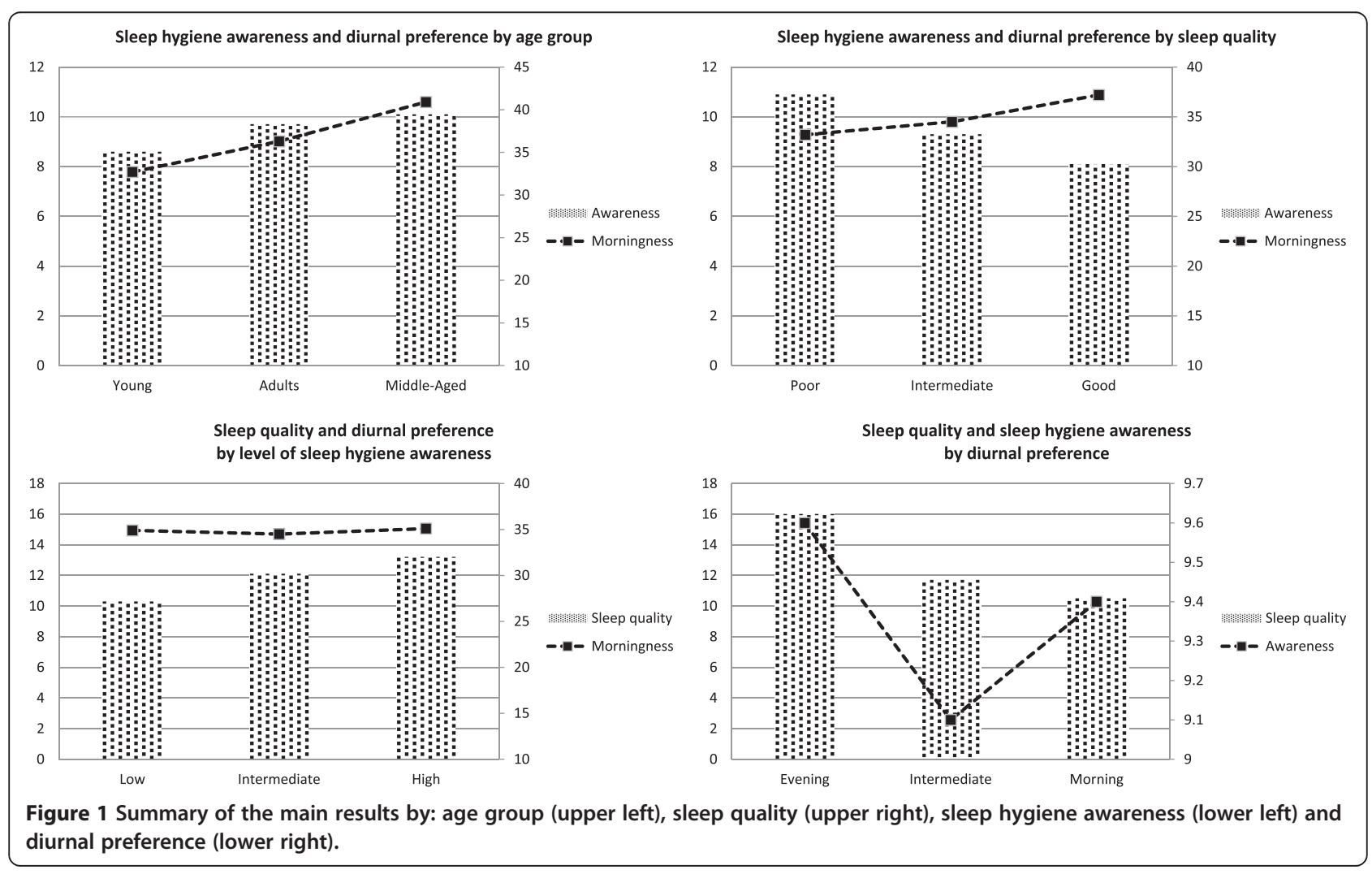


sleep patterns occur between age 19 and age 60 and that they decline only minimally after age 60 . One explanation is that total sleep time may not necessarily decrease with age, but the way in which sleep is consolidated becomes altered, e.g. by daytime napping, as around $15 \%$ of people aged over 55 years reporting to nap four to seven times per week [55].

Our results also suggest that better sleep hygiene awareness does not necessarily guarantee better sleep quality; on the contrary, sleep quality was better amongst those with poorer sleep hygiene awareness. Better sleep hygiene awareness was actually an indicator of dissatisfaction with the obtained sleep. Better sleep hygiene awareness does not imply a better sleep hygiene practice [12,41], probably because sleep hygiene is not found useful $[41,56]$ or is used wrongly [8], e.g. for an inadequate time or partially. It has been suggested that sleep hygiene must have played a much more important role several decades ago when the first sleep hygiene rules have been proposed [2]. Nowadays, access to information is easy and somebody unsatisfied with his or her sleep has usually already practiced some sleep hygiene by the time a sleep specialist is consulted. In this circumstances, the rationale of sleep hygiene is to optimize the outcomes (e.g. sleeping for 7 hours instead of 6 hours and a half) and to decrease the vulnerability to relapse/recurrence (e.g. lower the predisposition for insomnia) [2]. Although, current guidelines do not recommend sleep hygiene as a single therapy for insomnia [57] and many use brief sleep hygiene as a control condition in cognitive-behavioral treatment randomized trials [2], sleep hygiene might be more useful in certain groups, such as adolescents and young adults $[12-15,58]$ or workers $[59,60]$ as it can improve daily performance. Good sleepers, if aged under 65 years, might also benefit more from sleep hygiene than insomniacs [44]. On the other hand, the efficacy of sleep hygiene in those aged over 65 years is questionable, both in good and poor sleepers [11]. Still, when properly used together with behavioral sleep interventions, sleep hygiene is useful in alleviating insomnia symptomatology [2-6].

As we used the same or a similar instrument for determining sleep hygiene awareness like in other two studies $[14,19,28]$ we could make some comparisons with the reported data, using the information from participants aged under 25 years. Participants in our sample were better in identifying the negative effect of coffee on sleep, similar to those from Spain and far better than those from Italy or the US. Unlike the Americans, who "do not know" whether regular use of sleep medication, smoking/drinking alcohol in the evening or studying in bed have negative or positive effects on sleep, participants from Europe were aware of their negative consequences. About half of the latter group were unaware that getting up when it is difficult to sleep actually helps sleep. Unlike Romanian respondents, those from Italy and Spain knew that sleep is impaired by recovering lost sleep by sleeping longer, by trying to fall asleep without a sleep sensation, by worrying about not getting enough sleep or by going to bed with an empty stomach. American students were best in spotting thinking about one's engagements for the next day before sleep as a sleep detractor. These findings indicate that culture may influence sleep-hygiene practices and that cultural factors may increase the risk for or protect against poor sleep quality.

Several limitations should be acknowledged. Participants in this study were self-selected and a reason for them to volunteer might have been an already existing poor sleep or a higher level of conscientiousness. As data were collected online, we could not gather information from people who had had no internet access or had been unable to use a computer/mobile device. The percentage of male respondents was small, therefore the sample may not be representative for the population. One possible explanation is the recruitment of psychology students, where only a quarter of them are men [61]; this should be addressed in future studies by looking for student populations where male gender is better represented. Also, we did not measure participants' sleep-related behaviors (that may be different from their beliefs or attitudes) or the daytime sleepiness, which was found to be better linked with sleep hygiene than with sleep quality [62] and do not know how many participants have answered items in relation to their own sleep rather than in relation to the sleep of people in general, as they should have done. Finally, items about sleep hygiene awareness assume correct answers that overlook the possibility of individual differences in sensitivity or resilience.

\section{Conclusions}

In our sample, sleep hygiene awareness was moderate on the whole and significantly worse in young adults (compared to the other age groups) and in those complaining of poor sleep (compared to those with good sleep). Sleep quality was average and linked with diurnal preference (the more evening oriented, the poorer the sleep). We did not find diurnal preference to play a role regarding sleep hygiene awareness. Our results also suggest that better sleep hygiene awareness does not necessarily guarantee better sleep quality and that it may actually be an indicator of dissatisfaction with the obtained sleep.

\section{Endnote}

${ }^{\mathrm{a}}$ During the development of the scale, the authors changed the way the scale is scored. Initially, a higher score indicated a poorer sleep. The latest version has a reversed scoring: the higher the score, the better the sleep. 


\section{Availability of supporting data}

\section{Supporting data is available upon request form the corresponding author.}

\section{Competing interests}

The authors declare that they have no competing interests.

\section{Authors' contributions}

BV has made substantial contributions to 1) conception and design, acquisition of data, analysis and interpretation of data; 2) has been involved in drafting the manuscript or revising it critically for important intellectual content; 3 ) has given final approval of the version to be published; and 4) agrees to be accountable for all aspects of the work in ensuring that questions related to the accuracy or integrity of any part of the work are appropriately investigated and resolved.AS has made substantial contributions to 1) conception and design, interpretation of data; 2) has been involved in drafting the manuscript or revising it critically for important intellectual content; 3 ) has given final approval of the version to be published; and 4) agrees to be accountable for all aspects of the work in ensuring that questions related to the accuracy or integrity of any part of the work are appropriately investigated and resolved.

\section{Acknowledgments}

The authors thank Dr. Daniela Zaharie (Faculty of Psychology, "Alexandru loan Cuza" University, laşi, Romania) for the help in students' recruiting, as well as to SurveyGizmo (Colorado, USA, http://www.surveygizmo.com) for developing a comprehensive and complex web survey solution and for offering it for free as a student plan. Support for this work was provided by the Sectorial Operational Programme for Human Resources Development 2007-2013, co-financed by the European Social Fund, POSDRU 89/1.5/S/ 60189 "Postdoctoral Programs for Sustainable Development in a Knowledge Based Society".

\section{Received: 10 November 2014 Accepted: 20 January 2015}

Published online: 31 January 2015

\section{References}

1. American Academy of Sleep Medicine. International Classification of Sleep Disorders: Diagnostic and Coding Manual. 2nd ed. Westchester, IL, USA: American Academy of Sleep Medicine; 2005.

2. Perlis M, Aloia M, Kuhn B. Behavioral Treatments for Sleep Disorders. A Comprehensive Primer of Behavioral Sleep Medicine Interventions. London, UK: Academic Press; 2011.

3. Edinger J, Carne C. Overcoming Insomnia: Therapist Guide: A CognitiveBehavioral Therapy Approach. Treatments That Work. New York, USA: Oxford University Press; 2008.

4. Espie C. Overcoming Insomnia and Sleep Problems: A Self-Help Guide Using Cognitive Behavioral Techniques. London: Robinson Publishing; 2006.

5. Morin CM, Bootzin RR, Buysse DJ, Edinger JD, Espie CA, Lichstein KL. Psychological and behavioral treatment of insomnia:update of the recent evidence (1998-2004). Sleep. 2006;29(11):1398-414.

6. Perlis M, Jungquist C, Smith MT, Posner D. Cognitive Behavioral Treatment of Insomnia: A Session-by-Session Guide. New York: Springer Science; 2005.

7. Cheek RE, Shaver JL, Lentz MJ. Variations in sleep hygiene practices of women with and without insomnia. Res Nurs Health. 2004;27(4):225-36. doi:10.1002/nur.20025.

8. Gellis LA, Lichstein KL. Sleep hygiene practices of good and poor sleepers in the United States: an internet-based study. Behav Ther. 2009;40(1):1-9. doi:10.1016/j.beth.2008.02.001.

9. Harvey AG. Sleep hygiene and sleep-onset insomnia. J Nerv Ment Dis. 2000;188(1):53-5.

10. Stepanski EJ, Wyatt JK. Use of sleep hygiene in the treatment of insomnia. Sleep Med Rev. 2003;7(3):215-25.

11. McCrae CS, Rowe MA, Dautovich ND, Lichstein KL, Durrence HH, Riedel BW, et al. Sleep hygiene practices in two community dwelling samples of older adults. Sleep. 2006;29(12):1551-60.

12. Brown FC, Buboltz Jr WC, Soper B. Relationship of sleep hygiene awareness, sleep hygiene practices, and sleep quality in university students. Behav Med. 2002;28(1):33-8. doi:10.1080/08964280209596396.

13. LeBourgeois MK, Giannotti F, Cortesi F, Wolfson AR, Harsh J. The relationship between reported sleep quality and sleep hygiene in Italian and American adolescents. Pediatrics. 2005;115(1 Suppl):257-65. doi:10.1542/peds. 2004-0815H

14. Digdon NL. Circadian preference and college students' beliefs about sleep education. Chronobiol Int. 2010;27(2):297-317. doi:10.3109/ 07420520903502895

15. Suen LK, Hon KL, Tam WW. Association between sleep behavior and sleep-related factors among university students in Hong Kong. Chronobiol Int. 2008:25(5):760-75. doi:10.1080/07420520802397186.

16. Hicks RA, Fernandez C, Pellegrini RJ. The changing sleep habits of university students: an update. Percept Mot Skills. 2001;93(3):648. doi:10.2466/ pms.2001.93.3.648

17. Pallos H, Gergely V, Yamada N, Miyazaki S, Okawa M. The quality of sleep and factors associated with poor sleep in Japanese graduate students. Sleep Biol Rhythms. 2007;5(4):234-8. doi:10.1111/j.1479-8425.2007.00316.x.

18. Taylor DJ, Gardner CE, Bramoweth AD, Williams JM, Roane BM, Grieser EA, et al. Insomnia and mental health in college students. Behav Sleep Med. 2011:9(2):107-16. doi:10.1080/15402002.2011.557992.

19. Voinescu BI, Szentagotai A, David D. Sleep disturbance, circadian preference and symptoms of adult attention deficit hyperactivity disorder (ADHD). J Neural Transm. 2012;119(10):1195-204.

20. Lund HG, Reider BD, Whiting AB, Prichard JR. Sleep patterns and predictors of disturbed sleep in a large population of college students. J Adolesc Health. 2010;46(2):124-32. doi:10.1016/j.jadohealth.2009.06.016.

21. Eller T, Aluoja A, Vasar V, Veldi M. Symptoms of anxiety and depression in Estonian medical students with sleep problems. Depress Anxiety. 2006;23(4):250-6. doi:10.1002/da.20166.

22. Pilcher JJ, Ginter DR, Sadowsky B. Sleep quality versus sleep quantity: relationships between sleep and measures of health, well-being and sleepiness in college students. J Psychosom Res. 1997;42(6):583-96.

23. Curcio G, Ferrara M, De Gennaro L. Sleep loss, learning capacity and academic performance. Sleep Med Rev. 2006;10(5):323-37. doi:10.1016/ j.smrv.2005.11.001.

24. Edwards BA, O'Driscoll DM, Ali A, Jordan AS, Trinder J, Malhotra A. Aging and sleep: physiology and pathophysiology. Semin Respir Crit Care Med. 2010;31(5):618-33. doi:10.1055/s-0030-1265902

25. Bin YS, Marshall NS, Glozier N. Secular trends in adult sleep duration: a systematic review. Sleep Med Rev. 2012;16(3):223-30. doi:10.1016/ j.smrv.2011.07.003.

26. Carrier J, Monk TH, Buysse DJ, Kupfer DJ. Sleep and morningness-eveningness in the 'middle' years of life (20-59 y). J Sleep Res. 1997;6(4):230-7.

27. Taillard J, Philip P, Bioulac B. Morningness/eveningness and the need for sleep. J Sleep Res. 1999;8(4):291-5.

28. Adan A, Fabbri M, Natale V, Prat G. Sleep Beliefs Scale (SBS) and circadian typology. J Sleep Res. 2006;15(2):125-32. doi:10.1111/j.1365-2869.2006.00509.x

29. Caci H, Deschaux O, Adan A, Natale V. Comparing three morningness scales: age and gender effects, structure and cut-off criteria. Sleep Med. 2009:10(2):240-5. doi:10.1016/j.sleep.2008.01.007.

30. Paine SJ, Gander PH, Travier N. The epidemiology of morningness/ eveningness: influence of age, gender, ethnicity, and socioeconomic factors in adults (30-49 years). J Biol Rhythms. 2006;21(1):68-76. doi:10.1177/0748730405283154.

31. Monk TH. Aging human circadian rhythms: conventional wisdom may not always be right. J Biol Rhythms. 2005:20(4):366-74. doi:10.1177/ 0748730405277378.

32. Voinescu B, Coogan AN, Orasan R. Sleep beliefs, subjective sleep quality and diurnal preference - findings from depressed patients. J Cogn Behav Psychot. 2010;10(1):1-12. doi:10.1207/s15327752jpa6703_130165-1781(89)90047-4.

33. Espie CA, Kyle SD, Hames P, Gardani M, Fleming L, Cape J. The sleep condition indicator: a clinical screening tool to evaluate insomnia disorder. BMJ open. 2014;4(3):e004183. doi:10.1136/bmjopen-2013-004183.

34. Voinescu B, Szentagotai A. Categorical and dimensional assessment of insomnia in the general population. J Cogn Behav Psychot. 2013;13(1a):197-209.

35. Voinescu BI, Coogan AN, Thome J, Orasan R. Psychometric properties of the romanian version of the composite scale of morningness in healthy adults. Cogn Creier Comport Brain Behav. 2010;14(1):37-46.

36. Smith CS, Reilly C, Midkiff K. Evaluation of three circadian rhythm questionnaires with suggestions for an improved measure of morningness. J Appl Psychol. 1989;74(5):728-38.

37. Kovacic Z, Marendic M, Soljic M, Pecotic R, Kardum G, Dogas Z. Knowledge and attitude regarding sleep medicine of medical students and physicians in Split. Croatia Croat Med J. 2002;43(1):71-4. 
38. Ellis J, Hampson SE, Cropley M. Sleep hygiene or compensatory sleep practices: an examination of behaviours affecting sleep in older adults. Psychol Health Med. 2002;7(2):156-61. doi:10.1080/13548500120116094.

39. Díaz-Morales JF, Prieto PD, Barreno CE, Mateo MJC, Randler C. Sleep beliefs and chronotype among adolescents: the effect of a sleep education program. Biol Rhythm Res. 2012;43(4):397-412. doi:10.1080/ 09291016.2011.597620.

40. Magnúsdóttir SD, Ribacke M. Patients' knowledge and attitudes regarding sleep and hypnotics. Scand J Prim Health Care. 1996;14(2):106-10. doi:10.3109/02813439608997079.

41. Gallasch J, Gradisar M. Relationships between sleep knowledge, sleep practice and sleep quality. Sleep Biol Rhythm. 2007:5(1):63-73.

42. Altun I, Cinar N, Dede C. The contributing factors to poor sleep experiences in according to the university students: a cross-sectional study. J Res Med Sci. 2012;17(6):557-61.

43. Sivagnanam G, Thirumalaikolundusubramanian P, Sugirda P, Rajeswari J, Namasivayam K, Gitanjali B. Study of the knowledge, beliefs, and practice of sleep among medical undergraduates of Tamilnadu, India. MedGenMed. 2004;6(4):5.

44. Yang CM, Lin SC, Hsu SC, Cheng CP. Maladaptive sleep hygiene practices in good sleepers and patients with insomnia. J Health Psychol. 2010;15(1):147-55. doi:10.1177/1359105309346342.

45. Bosie GD, Tefera TW, Hailu GS. Knowledge, attitude and practice with respect to sleep among undergraduate medical students of Mekelle University. Sleep Biol Rhythms. 2012;10(4):264-9. doi:10.1111/j.1479-8425.2012.00569.x

46. Chung MH, Chang FM, Yang CC, Kuo TB, Hsu N. Sleep quality and morningness-eveningness of shift nurses. J Clin Nurs. 2009;18(2):279-84. doi:10.1111/j.1365-2702.2007.02160.x.

47. Mongrain V, Carrier J, Dumont M. Circadian and homeostatic sleep regulation in morningness-eveningness. J Sleep Res. 2006;15(2):162-6. doi:10.1111/j.1365-2869.2006.00532.x.

48. Martin JS, Hebert M, Ledoux E, Gaudreault M, Laberge L. Relationship of chronotype to sleep, light exposure, and work-related fatigue in student workers. Chronobiol Int. 2012;29(3):295-304. doi:10.3109/07420528.2011.653656.

49. Soehner AM, Kennedy KS, Monk TH. Circadian preference and sleep-wake regularity: associations with self-report sleep parameters in daytime-working adults. Chronobiol Int. 2011;28(9):802-9. doi:10.3109/07420528.2011.613137.

50. Leger D, Roscoat E, Bayon V, Guignard R, Paquereau J, Beck F. Short sleep in young adults: Insomnia or sleep debt? Prevalence and clinical description of short sleep in a representative sample of 1004 young adults from France. Sleep Med. 2011;12(5):454-62. doi:10.1016/j.sleep.2010.12.012.

51. Fernandez-Mendoza J, Ilioudi C, Montes MI, Olavarrieta-Bernardino S, Aguirre-Berrocal A, De La Cruz-Troca JJ, et al. Circadian preference, nighttime sleep and daytime functioning in young adulthood. Sleep Biol Rhythm. 2010;8(1):52-62. doi:10.1111/j.1479-8425.2010.00430.x.

52. Lehnkering $H$, Siegmund R. Influence of chronotype, season, and sex of subject on sleep behavior of young adults. Chronobiol Int. 2007;24(5):875-88. doi:10.1080/07420520701648259.

53. Brick CA, Seely DL, Palermo TM. Association between sleep hygiene and sleep quality in medical students. Behav Sleep Med. 2010;8(2):113-21. doi:10.1080/15402001003622925.

54. Ohayon MM, Carskadon MA, Guilleminault C, Vitiello MV. Meta-analysis of quantitative sleep parameters from childhood to old age in healthy individuals: developing normative sleep values across the human lifespan. Sleep. 2004;27(7):1255-73.

55. Foley DJ, Vitiello MV, Bliwise DL, Ancoli-Israel S, Monjan AA, Walsh JK. Frequent napping is associated with excessive daytime sleepiness, depression, pain, and nocturia in older adults: findings from the national sleep foundation '2003 sleep in America' poll. Am J Geriatr Psychiatr. 2007;15(4):344-50.

56. Jefferson CD, Drake CL, Scofield HM, Myers E, McClure T, Roehrs T, et al. Sleep hygiene practices in a population-based sample of insomniacs. Sleep. 2005;28(5):611-5.

57. Morgenthaler TI, Lee-Chiong T, Alessi C, Friedman L, Aurora RN, Boehlecke $B$, et al. Practice parameters for the clinical evaluation and treatment of circadian rhythm sleep disorders. An american academy of sleep medicine report. Sleep. 2007;30(11):1445-59.

58. Billows M, Gradisar M, Dohnt H, Johnston A, McCappin S, Hudson J. Family disorganization, sleep hygiene, and adolescent sleep disturbance. Journal of clinical child and adolescent psychology: the official journal for the Society of Clinical Child and Adolescent Psychology, American Psychological Association, Division 53. 2009;38(5):745-52. doi:10.1080/15374410903103635.

59. Barber L, Grawitch MJ, Munz DC. Are Better Sleepers More Engaged Workers? A Self-regulatory Approach to Sleep Hygiene and Work Engagement. Stress and health: journal of the International Society for the Investigation of Stress. 2012. doi:10.1002/smi.2468.

60. Chen PH, Kuo HY, Chueh KH. Sleep hygiene education: efficacy on sleep quality in working women. J Nurs Res. 2010;18(4):283-9. doi:10.1097/ JNR.0b013e3181fbe3fd.

61. Skinner K, Louw J. The feminization of psychology: data from South Africa. Int J Psychol. 2009;44(2):81-92. doi:10.1080/00207590701436736.

62. Mastin DF, Bryson J, Corwyn R. Assessment of sleep hygiene using the sleep hygiene index. J Behav Med. 2006;29(3):223-7. doi:10.1007/s10865-006-9047-6.

\section{Submit your next manuscript to BioMed Central and take full advantage of:}

- Convenient online submission

- Thorough peer review

- No space constraints or color figure charges

- Immediate publication on acceptance

- Inclusion in PubMed, CAS, Scopus and Google Scholar

- Research which is freely available for redistribution 